\title{
LIFE QUALITY IN IRAQI CHILDREN AND ADOLESCENTS LIVING IN AREAS OF ARMED CONFLICT
}

\author{
Iuliia Pavlova \\ Lviv State University of Physical Culture, Ukraine \\ Bogdan Vynogradskyi \\ Lviv State University of Physical Culture, Ukraine
}

Ali Abdulkareem Jassim Al Ubaidi

Lviv State University of Physical Culture, Ukraine

\begin{abstract}
The aim of the paper was to analyze the quality of life (QL) of Iraqi children and adolescents, and identify which aspects of functioning had the greatest impact on the overall assessment of the well-being in this population group. Participants were healthy children aged 5-18 years ( $n=150,50 \%$ females) who studied in Baghdad schools. QL was assessed using PedsQL questionnaire by four scales - physical (PF), emotional (EF), social (SF), and school functioning (SchF). Samples were compared using the Kruskal-Wallis test. An exploratory factor analysis was performed to understand the structure of $Q L$. The QL of Iraqi children was moderate. The highest level of PF, SF, and SchF had persons aged 13-18 years $(p<0.05)$. Females had a higher level of $Q L(p<0.05)$, regardless of age. It was established that the data was convenient for factor analysis $\left(K M O=0.753, \chi^{2}=110.047 ; p=0.000\right)$. The results showed that the varimax method presents the best fit. Factor analysis supported the 2-component model that explained $73.86 \%$ of the total variance.
\end{abstract}

Keywords: factor analysis, Iraq, PedsQL, quality of life, school students.

\section{Introduction}

Before the war in 1980, Iraq was a country that had been actively developing and with high-quality healthcare and education systems (Rawaf et al., 2014). However, numerous military conflicts, which have been occurring from 1990 to the present day, as well as terrorist threats, mass protests, guerrilla warfare, and international sanctions, have destroyed the livelihoods and infrastructure and completely changed the situation in this country. Nowadays, the standard of living of the population has worsened significantly, the socio-economic conditions in the country are unsatisfactory, the unemployment rate is constantly growing, services are provided but of very poor quality or none at all. The basic human needs remain unfulfilled - safety, protection, water, and food. 
Pavlova et al., 2020. Life Quality in Iraqi Children and Adolescents

Living in Areas of Armed Conflict

WHO estimates that the humanitarian crisis in Iraq remains one of the most threatening in the world, but it represents the greatest danger to the human resource of the country itself. Half of the population of Iraq are people under the age of 19 (World Health Organization. Iraq Health Profile, 2011), and most of them are socially vulnerable, often unable to identify and meet their own needs people. The concept of health-related quality of life allows to evaluate the physical, mental and social aspects of well-being from the children's or adolescent's point of view, characterize their functional and cognitive abilities, identify life-critical aspects of their being, carry out daily and professional activities, and perform social roles (Wallander \& Koot, 2016).

General and specialized methods are used to determine the quality of life. They allow evaluating some specific aspects of life (physical, and mental states, physical, and social activity). Pediatric Quality of Life Inventory (PedsQL) has been translated into more than 70 languages (Caocci et al., 2011; Raj et al., 2017; Viira \& Koka, 2011); it is a validated tool (Varni, Limbers, \& Burwinkle, 2007; Varni, Seid, \& Rode, 1999) that aims at analyzing the negative aspects of daily functioning, in particular identifying those aspects that have been an issue for the children over the past month. The tool has been adapted for persons of different ages; its basic part can be used both for healthy people, and for those with chronic or acute diseases.

The goal of the work was to analyze the quality of life of Iraqi children and young people, considering the socio-demographic factors and identify which aspects of functioning have the most influence on the overall assessment of the quality of life of this group of respondents.

\section{Methods}

\section{Study sample}

Participants were healthy children aged 5-18 years ( $\mathrm{n}=150,50 \%$ females) who studied at schools in Baghdad. The study was conducted in the 2018-2019 academic year. Participants were informed about the goals and objectives of the study and could refuse to participate in it at any time.

\section{Research tool}

Quality of life has been assessed using the Generic Core Scales of Pediatric Quality of Life Inventory (PedsQL ${ }^{\mathrm{TM}}$ 4.0) (Varni et al., 1999; Varni et al., 2007). Permission to use the validated Arabic version of the questionnaire (self-reports) for children aged 5-7, 8-12, and 13-18 years has been granted by Mapi Research Trust (Lyon, France) that is the right holder organization of the methodology.

The PedsQL consists of 23 questions, which are grouped into four separate blocks. The answers to each question are formed using a 5-point Likert scale (answer options are "Never," “Almost never," "Sometimes," “Often,” and 
"Almost always"). Based on the results of the survey, it is possible to assess the value of quality of life on the scales of Physical Functioning (PF), Emotional Functioning (EF), Social Functioning (SF), and School Functioning (SchF). The PedsQL total score has been composed of the Physical Health Summary (identical to the Physical Functioning) and psychosocial scores. Psychosocial Health Summary (PHS) has been calculated using Emotional, Social, and School Functioning. The importance of the quality of life on each scale has been measured in points; the maximum indicator is 100 points, the minimum -0 points. If the respondent does not answer more than half of the questions in a separate block, then the final indicator on this scale is not calculated. The value under 50 points has been interpreted as very poor/poor quality of life, 51-75 points moderate, and above 75 points - high (Sasi et al., 2016).

Statistical analysis

The following software has been used for the statistical processing of data: Origin Pro 8.6, and IBM SPSS Statistics V. 23 (SPSS Inc., Chicago, Illinois, USA). The mean (M), corrected standard deviation (SD), standard error (SE), and confidence intervals (CI) have been determined. Samples have been compared using the Kruskal-Wallis test. The differences have been considered to be significant at $\mathrm{p}<0.05$.

An exploratory factor analysis (EFA) has been performed to understand the structure of quality of life using maximum likelihood estimation and varimax rotation. The data of four general scales (PF, EF, SF, and SchF) have been used. The Kaiser-Meyer-Olkin Measure (KMO test) of sampling adequacy and Bartlett's test of sphericity have been used before the EFA. The KMO test presents normalized values (ranged from 0 to 1.0); values close to 1.0 indicate that the factor analysis method has been perfectly suited for the data processing. The Bartlett's test of sphericity is based on the statistical chi-square distribution; it tests the null hypothesis. Levels of significance $>0.1$ indicate that the data cannot be used.

\section{Results}

The quality of life of the respondents has been average (Table 1) and has not exceeded 66 points on all scales. The values of PF and PHS scales have been statistically significantly different $(\mathrm{p}<0.001)$. The highest results have been observed for the PF (64.69 \pm 24.38 points) and SF (65.90 \pm 23.08 points), and EF has been of the lowest value ( $54.78 \pm 26.41$ points). 
Pavlova et al., 2020. Life Quality in Iraqi Children and Adolescents Living in Areas of Armed Conflict

Table 1 Quality of life for people aged 5-18 years

\begin{tabular}{|l|c|c|c|}
\hline Scales & $\mathbf{M} \pm$ SE & SD & 95\% CI \\
\hline Physical Functioning & $64.69 \pm 2.19^{*}$ & 24.38 & $60.36 ; 69.03$ \\
\hline Psychosocial Health Summary & $61.23 \pm 1.94^{*}$ & 21.00 & $57.38 ; 65.07$ \\
Emotional Functioning & $54.78 \pm 2.39$ & 26.41 & $50.05 ; 59.52$ \\
Social Functioning & $65.90 \pm 2.07$ & 23.08 & $61.80 ; 70.00$ \\
School Functioning & $63.35 \pm 2.90$ & 31.46 & $57.61 ; 69.08$ \\
\hline
\end{tabular}

Notes. ${ }^{*}$ - there were statistically significant differences between these scales $(p<0.001)$

Similar differences have been observed in respondent groups of different ages (Table 2). The highest SF scale indicator (70.2 \pm 23.77 points) has been observed among children of 5-7 years of age; in individuals aged 13-18 years PF (81.51 \pm 16.31 points) and SchF (74.39 \pm 18.10 points). The values of PF and PHS scales within the age group of 5-7 years and 13-18 years have been statistically significantly different $(\mathrm{p}<0.05)$, but among the respondents aged 8 12 years, the indicators of these scales have been at the same level $(p>0.2)$.

Table 2 Quality of life of respondents of different ages

\begin{tabular}{|c|c|c|c|}
\hline Scales & $\mathrm{M} \pm \mathrm{SE}$ & SD & $95 \% \mathrm{CI}$ \\
\hline \multicolumn{4}{|c|}{$5-7$ years $(n=50)$} \\
\hline Physical Functioning & $55.32 \pm 7.14^{*}, \dagger$ & 35.68 & $40.59 ; 70.05$ \\
\hline Psychosocial Health Summary & $61.50 \pm 5.95^{*}, \dagger$ & 29.77 & $49.21 ; 73.79$ \\
\hline Emotional Functioning & $56.70 \pm 6.41$ & 32.04 & $43.48 ; 69.92$ \\
\hline Social Functioning & $70.2 \pm 4.75^{\dagger}$ & 23.77 & $60.39 ; 80.01$ \\
\hline School Functioning & $57.60 \pm 8.09^{\dagger}$ & 40.44 & $40.91 ; 74.29$ \\
\hline \multicolumn{4}{|c|}{$8-12$ years $(n=50)$} \\
\hline Physical Functioning & $52.91 \pm 1.67^{* *}$, & 11.78 & $49.56 ; 56.25$ \\
\hline Psychosocial Health Summary & $54.51 \pm 2.74^{* *}$, & 17.94 & $48.99 ; 60.03$ \\
\hline Emotional Functioning & $52.37 \pm 3.37^{\ddagger}$ & 23.34 & $45.59 ; 59.14$ \\
\hline Social Functioning & $59.34 \pm 3.24^{\ddagger}$ & 22.91 & $52.83 ; 65.85$ \\
\hline School Functioning & $54.32 \pm 5.16^{\ddagger}$ & 34.25 & $43.91 ; 64.73$ \\
\hline \multicolumn{4}{|c|}{$13-18$ years $(n=50)$} \\
\hline Physical Functioning & $81.51 \pm 2.33^{*}, \dagger$ & 16.31 & $76.82 ; 86.19$ \\
\hline Psychosocial Health Summary & $66.98 \pm 2.34^{*}, \dagger$ & 16.35 & $62.29 ; 71.68$ \\
\hline Emotional Functioning & $56.16 \pm 3.79$ & 26.50 & $48.55 ; 63.78$ \\
\hline Social Functioning & $70.40 \pm 3.10^{\dagger}$ & 21.73 & $64.16 ; 76.64$ \\
\hline School Functioning & $74.39 \pm 2.59^{\dagger}$ & 18.10 & $69.19 ; 79.59$ \\
\hline
\end{tabular}

Notes. ${ }^{*}$ - the value of all scales within the age group is statistically significantly different $(p<0.05) ;^{* *}$ - the value of all scales within the age group is not statistically significantly different $(p>0.2) ;^{+}-$the quality of life of the respondents aged 5-7 years and 13-18 years of age is statistically significantly different on the corresponding scales $(p<0.05) ;{ }^{*}$ - the quality of life of people aged 8-12 years on the corresponding scales is the lowest in comparison with other age groups $(p<0.05-0.1)$ 
Individuals aged 8-12 years have a poor quality of life, and all indicators have not exceeded 60 points. In general, all respondents in this age group have a poor or lower than moderate quality of life; confidence intervals have been in the range of 40-60 points. On all scales, the quality of life of this age group is lower $(\mathrm{p}<0.1)$ compared to other groups.

Comparing with the respondents of 5-7 years of age, 13-18-year-old individuals have a higher $(\mathrm{p}<0.05)$ quality of life on the PF (81.50 points), SF (70.39 points) and SchF (74.39 points) scales. The EF value for these age groups has neither differed $(\mathrm{p}>0.5)$ nor exceeded 57 points.

The females have accounted for a higher quality of life compared with the scales of both physical and psychosocial functioning. The best quality of life has been observed on the scale of SF (67.84 \pm 2.97 points), and a lower one on the scale of EF (51.52 \pm 3.36 points). The values of all scales have been significantly different amongst themselves $(\mathrm{p}<0.05)$. Male's quality of life has been lower than female's and has not exceeded 63.0 points. Statistically significant differences have been observed for the PF and SchF scales $(\mathrm{p}<0.05)$, the difference between the indicators of these scales has reached 10 points. Similar patterns have been revealed at comparing the quality of life of males and females in each age group (Fig. 1). For females and males of 13-18 years of age, the indicators have been different on the scales of PF and EF; for the age group of 8-12 years - on the PHS scale; for the age group of 5-7 years - on the scales of PF and SF.

In order to find out whether the data collected are appropriate to the EFA, KMO coefficient and Bartlett's test of sphericity, - all the values have been calculated $(\mathrm{KMO}=0.753, \chi 2=110.047 ; \mathrm{p}=0.000)$. It has been established that the data are convenient for the factor analysis.

The results have shown that the varimax method presents the best fit. This extraction method minimizes the number of factors needed to explain each variable. Factor analysis supports a 2-component model that explains 73.86\% of the total variance. After identifying the factor loadings of the four main PedsQL scales, it has been found that the eigenvalue of the first component has been 2.287, the explained variance ratio has constituted 57.173, the eigenvalue of the second component has made up 0.667, and the explained variance ratio has reached 16.687. The factor loadings of the items forming the first component have amounted between 0.520 and 0.822 , and the factor loadings of the items of the second component have been between 0.132 and 0.706 (Table 3). 
Pavlova et al., 2020. Life Quality in Iraqi Children and Adolescents

Living in Areas of Armed Conflict

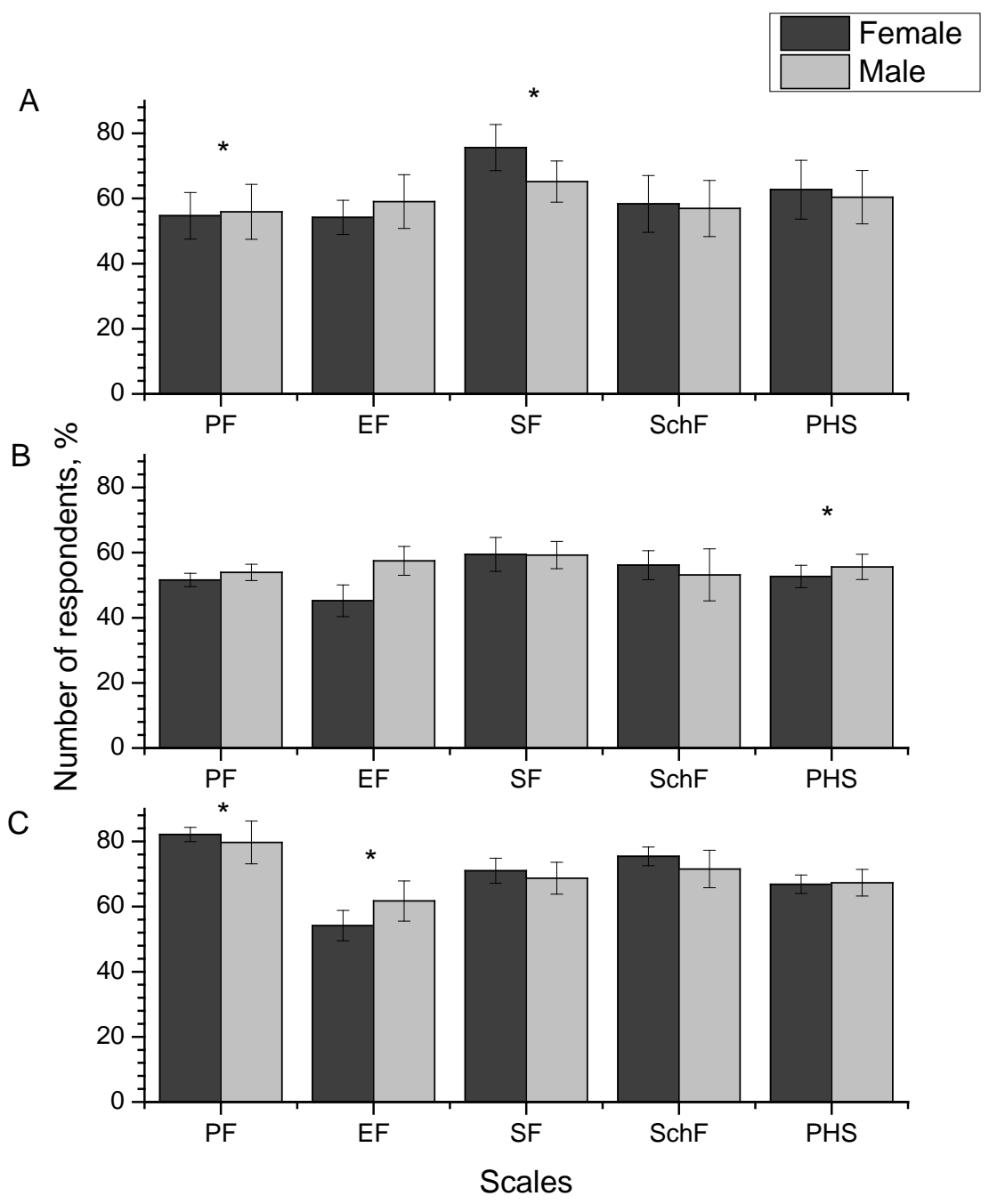

Figure 1 The quality of life of people of different ages and sex:

$A$ - people aged 5-7 years, $B$ - people aged 8-12 years, $C$ - people aged 13-18 years.

* - the quality of life of females and males on this scale differs $(p<0.05)$.

PF - Physical Functioning, EF - Emotional Functioning, SF - Social Functioning,

SchF - School Functioning, PHS - Psychosocial Health Summary

Table 3 Factor analysis of quality of life data

\begin{tabular}{|l|c|c|}
\hline \multirow{2}{*}{ Scale } & \multicolumn{2}{|c|}{ Component } \\
\cline { 2 - 3 } & 1 & 2 \\
\hline Physical Functioning & $\mathbf{0 . 8 2 2}$ & 0.132 \\
\hline Emotional Functioning & 0.520 & $\mathbf{0 . 7 0 6}$ \\
\hline Social Functioning & 0.608 & 0.359 \\
\hline School Functioning & $\mathbf{0 . 7 9 1}$ & 0.152 \\
\hline
\end{tabular}

The results of the survey of the respondents have been analyzed in more detail precisely on these scales (PF, SchF, and to a somewhat lesser extent on the scale of EF) since they are decisive for the general indicator of life quality 
according to the results of the factor analysis. From 14 to $45 \%$ of the respondents have had problems with daily activity - the most critical for the respondents have been weight lifting (45.2\% of the respondents), personal care (taking a bath or shower $-36.3 \%$ of the respondents), housework (38.7\%), and lack of strength (28.2\%) (Fig. 2). The level of activity in the school has been reduced in 18.6$37.1 \%$ of the children. One in four to five respondents negatively assesses his/her abilities when comparing himself/herself with other peers, and poorly concentrates and performs tasks in the classroom. The relative number of individuals has admitted having troubles with memorization that makes up 37.1\%; $23.4 \%$ regularly miss classes to visit a doctor.

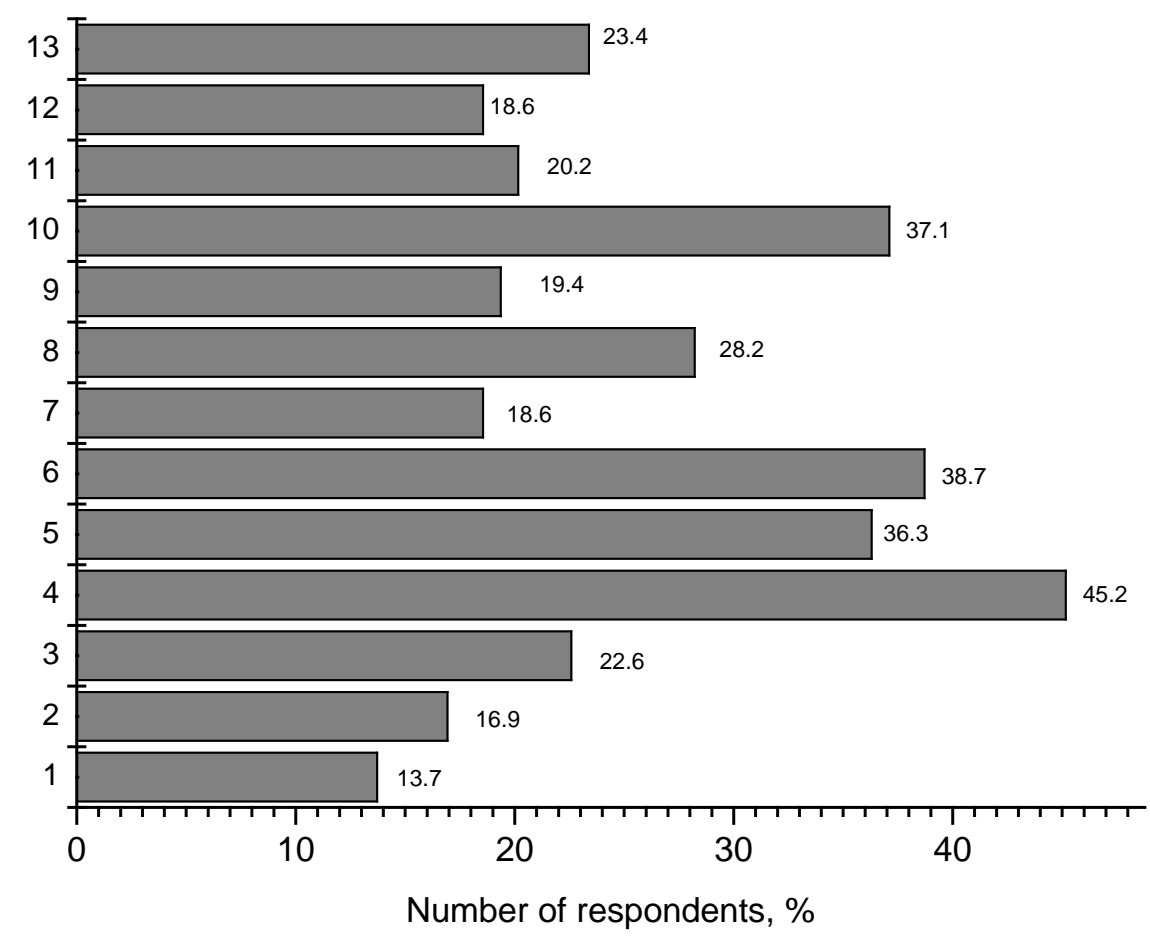

Figure 2 Subjective assessment of physical and social functioning:

the respondents have noted that they often, or almost always: 1 - have difficulties with walking more than one quarter; 2 - have difficulties with running; 3 - have difficulties with going in for sports or doing exercises; 4 - have trouble with lifting heavy stuff;

5 - have difficulties with taking a bath or shower; 6 - find it difficult to help with housework;

7 - have pain; 8 - have little strength; 9 - find it difficult to concentrate on classes in the classroom; 10 - find it difficult to remember something; 11 - find it difficult to keep up with school tasks; 12 -drop out of school due to poor health; 13 -miss classes to see the doctor or go to hospital

The following problems are critical for the emotional functioning of the respondents: sleep (25\% of the respondents have noted that they always or almost 
Pavlova et al., 2020. Life Quality in Iraqi Children and Adolescents

Living in Areas of Armed Conflict

always have problems with sleep), fear (39.51\%), grief (34.67\%), anger (34.91\%), and anxiety about the future (39.51\%). A smaller part of the respondents have mentioned problems with communication - difficulties in establishing relations with others (15.32\%), having trouble making friends $(10.48 \%)$, bullying (17.74\%), etc.

\section{Discussion}

Assessing the quality of life of children and adolescents is essential for the search and analysis of critical factors affecting the physical and mental health of the younger generation and, in general, allows identifying the need for this group of the population in medical services. Children who have complaints about physical functioning or who do not have a satisfactory assessment of their school environment more often visit a healthcare professional for a month (Rajmil et al., 2006).

Nowadays, with the help of the PedsQL questionnaire, the quality of life of children from different countries of the world with different health conditions has been studied, in particular, health-related life quality of Iraqi children with chronic diseases (Caocci et al., 2011), refugees living in Australia (Ziaian, Anstiss, Antoniou, Puvimanasinghe, \& Baghurst, 2016), however, there are no studies on the life quality of healthy children of different ages living in Iraq. The quality of life of the population studied by us has several features that differ from other countries of the world - lower rates are typical to young people and males. The scale of Physical Functioning is decisive in the overall assessment of the quality of life, and along with the scale of Social Functioning explains 57\% of the variance.

The results we have attained can be regarded as threatening, since the youngest part of the population have significantly lower quality of life than children with severe chronic diseases living in other countries of the world (Başgül, Üneri, \& Çakin-Memik, 2011; Upton, Lawford, \& Eiser, 2008; Varni et al., 2007). It should be noted that the quality of life associated with health, in general, does not tend to improve with age; indicators of Physical Functioning decrease, but Emotional Functioning may remain at a relatively stable level, or even improve. The quality of life of the examined children on all scales is less than 30 points lower than that of the US citizens (Varni et al., 2007), Brazil (Klatchoian et al., 2008), Sweden (Petersen, Hägglöf, Stenlund, \& Bergström, 2009), Estonia (Viira \& Koka, 2011), India (Raj et al., 2017), China (Ji et al., 2011), and Ukraine (Pavlova, 2015). So, for example, the general indicator of the quality of life of Indian people aged 5-7 years is $90.4 \pm 8.1$ points (Raj et al., 2017), and the value of individual scales is not lower than 80.3 points; the quality of life of children from Brazil (Klatchoian et al., 2008) makes up $88.9 \pm 7.4$ points; 
the life quality of children from Ukraine (Pavlova, 2015; Pavlova, Vynogradskyi, Ripak, Zikrach \& Borek, 2016), Jordan, and Palestine (Arabiat, Elliott, Draper, \& Al Jabery, 2011) amounts between 73-82 points. Comparison of the obtained data with other results (Varni et al., 1999; Varni et al., 2007), indicates that the healthrelated life quality of refugee children and adolescents living in other countries of the world, including their physical, emotional, social and school functioning, cannot be compared with the general pediatric population, and that in turn means that a significant part of the respondents who have participated in our study suffer or have chronic health problems.

A significant factor contributing to the poor health status of children and youth is mental and emotional problems (Lisiecka et al., 2016). Studies on Iraq in this direction are unique (“An unbearable reality,” 2017; Bolton, 2013) and allow only a superficial assessment of this issue. According to the Iraq Mental Health Survey, anxiety and depressive disorders have been common to $13.8 \%$ of the population. The report which focus on the impact of war and displacement indicates that Iraqi society is experiencing a high level of violence and various restrictions that cause toxic stress. Collective trauma in society is often a trigger for the development of domestic violence and aggressive behavior.

\section{Limitation}

The present findings have several potential limitation. The sample size in this study was relatively small compared to prior studies (Ji et al., 2011; Klatchoian et al., 2008; Pavlova, 2015; Petersen, Hägglöf, Stenlund, \& Bergström, 2009; Raj et al., 2017; Viira \& Koka, 2011). The results of factor analysis indicated a typical two-factor solution, but the general life quality result was largely due to the predominance of Physical and School Functioning in the aggregate figure. No comparison was analyzed between healthy children and children with different types of disability, as well as parent-proxy reports was also not tested. Therefore, we recommend further study with larger samples to analyze for age and gender based differences, and identification of the main components of the factor structure of well-being.

\section{Conclusions}

Experience of Iraqi children with violence and displacement affects their mental health and psychosocial needs, and the child's condition depends on how long he/she has been in the war zone or lost loved ones. The lack of targeted and long-term aid will have prolonged negative effects on this generation. The younger population was, the significantly lower quality of life was observed. The child's population has a lower quality of life than children with severe chronic 
Pavlova et al., 2020. Life Quality in Iraqi Children and Adolescents

Living in Areas of Armed Conflict

diseases from other countries.

The highest level of Physical, Social, and School functioning had persons aged 13-18 years. Females had a higher level of life quality, regardless of age. For the overall life quality, physical and school functioning was essential (explained variance ratio was 57.173).

\section{References}

An unbearable reality. (2017). 44. Retrieved from http://www.resourcecentre.savethechildren. net/library/unbearable-reality-impact-war-and-displacement-childrens-mental-healthiraq

Arabiat, D., Elliott, B., Draper, P., \& Al Jabery, M. (2011). Cross-cultural Validation of the Pediatric Quality of Life InventoryTM 4.0 (PedsQLTM) generic core scale into Arabic Language. Scandinavian Journal of Caring Sciences, 25(4), 828-833. DOI: https://doi.org/10.1111/j.1471-6712.2011.00889.x

Başgül, Ş.S., Üneri, Ö.Ş., \& Çakin-Memik, N. (2011). Parents’ perception of the quality of life of children with intellectual disabilities. Turkish Journal of Pediatrics, 53(5), 541-546.

Bolton, P. (2013). Mental health in Iraq: Issues and challenges. Lancet, Mar 16; 381(9870), 879-81. DOI: https://doi.org/10.1016/S0140-6736(13)60637-6

Caocci, G., Efficace, F., Ciotti, F., Roncarolo, M.G., Vacca, A., Piras, E., ... \& La Nasa, G. (2011). Prospective Assessment of Health-Related Quality of Life in Pediatric Patients with Beta-Thalassemia following Hematopoietic Stem Cell Transplantation. Biology of Blood and Marrow Transplantation, 17(6), 861-866. DOI: https://doi.org/10.1016/ j.bbmt.2010.09.011

Ji, Y., Chen, S., Li, K., Xiao, N., Yang, X., Zheng, S., \& Xiao, X. (2011). Measuring healthrelated quality of life in children with cancer living in mainland China: feasibility, reliability and validity of the Chinese mandarin version of PedsQL 4.0 Generic Core Scales and 3.0 Cancer Module. Health and Quality of Life Outcomes, 9(1), 103. DOI: https://doi.org/10.1186/1477-7525-9-103

Klatchoian, D.A., Len, C.A., Terreri, M.T.R.A., Silva, M., Itamoto, C., Ciconelli, R.M., ... \& Hilário, M.O.E. (2008). Qualidade de vida de crianças e adolescentes de São Paulo: confiabilidade e validade da versão brasileira do questionário genérico Pediatric Quality of Life InventoryTM versão 4.0. Jornal de Pediatria, 84(4), 308-315. DOI: https://doi.org/10.1590/S0021-75572008000400005

Lisiecka, K., Cieślik, M., Kolisetska, A., Wyszomierska, J., Stachowicz M., ... \& Wąsik, J. (2016). Constructive and destructivemethods of copying with anger at students measurement trial in an international perspective. Physical Activity Rev, 4, 200-3. DOI: https://doi.org/10.16926/par.2016.04.25

Pavlova, I. (2015). Life quality and health of children and youth of Ukraine. Slobozhanskyi Herald of Science and Sport, 46(2), 148-153. DOI: https://doi.org/10.15391/snsv.20152.029

Pavlova, I., Vynogradskyi, B., Ripak, I., Zikrach, D., \& Borek, Z. (2016). Prognostication of health-related life quality of ukrainian residents due to physical activity level. Journal of Physical Education and Sport, 16(2) 418-423. DOI: https://doi.org/10.7752/ jpes.2016.02065

Petersen, S., Hägglöf, B., Stenlund, H., \& Bergström, E. (2009). Psychometric properties of the Swedish PedsQL, Pediatric Quality of Life Inventory 4.0 generic core scales. Acta 
Paediatrica, 98(9), 1504-1512. DOI: https://doi.org/10.1111/j.1651-2227.2009.01360.x

Raj, M., Sudhakar, A., Roy, R., Champaneri, B., Joy, T.M., \& Kumar, R.K. (2017). Healthrelated quality of life in Indian children: A community-based cross-sectional survey. The Indian Journal of Medical Research, 145(4), 521. DOI: https://doi.org/10.4103/ IJMR.IJMR_447_16

Rajmil, L., Alonso, J., Berra, S., Ravens-Sieberer, U., Gosch, A., Simeoni, M.C., \& Auquier, P. (2006). Use of a children questionnaire of health-related quality of life (KIDSCREEN) as a measure of needs for health care services. Journal of Adolescent Health, 38(5), 511518. DOI: https://doi.org/10.1016/j.jadohealth.2005.05.022

Rawaf, S., Hassounah, S., Dubois, E., Abdalrahman, B., Raheem, M., Jamil, H., \& Majeed, A. (2014). Living conditions in Iraq: 10 years after the US-led invasion. Journal of the Royal Society of Medicine, 107(5), 187-193. DOI: https://doi.org/10.1177/0141076814530684

Sasi, V., Kamala, S., Padmaraj, R., \& Felix, J.W. (2016). Quality of life in children with chronic kidney disease - a parental report. Asia Pacific Journal of Research, 1(37), 39-42.

Upton, P., Lawford, J., \& Eiser, C. (2008). Parent-child agreement across child health-related quality of life instruments: a review of the literature. Quality of Life Research, 17(6), 895913. DOI: https://doi.org/10.1007/s11136-008-9350-5

Varni, J.W., Limbers, C.A., \& Burwinkle, T.M. (2007). Impaired health-related quality of life in children and adolescents with chronic conditions: a comparative analysis of 10 disease clusters and 33 disease categories/severities utilizing the PedsQL 4.0 Generic Core Scales. Health and Quality of Life Outcomes, 5, 43. DOI: https://doi.org/10.1186/14777525-5-43

Varni, J.W., Seid, M., \& Rode, C.A. (1999). The PedsQL: measurement model for the pediatric quality of life inventory. Medical Care, 37(2), 126-139.

Viira, R., \& Koka, A. (2011). Health-related quality of life of Estonian adolescents: reliability and validity of the PedsQLTM 4.0 Generic Core Scales in Estonia. Acta Paediatrica, 100(7), 1043-1047. DOI: https://doi.org/10.1111/j.1651-2227.2011.02193.x

Wallander, J.L., \& Koot, H.M. (2016). University of California issues, and future directions. Clinical Psychology Review, 45, 131-143. DOI: 10.1016/j.cpr.2015.11.007

World Health Organization. Iraq Health Profile. (2011). Retrieved from https://www.who.int/ gho/countries/irq.pdf

Ziaian, T., Anstiss, H. de, Antoniou, G., Puvimanasinghe, T., \& Baghurst, P. (2016). Sociodemographic Predictors of Health-Related Quality of Life and Healthcare Service Utilisation among Young Refugees in South Australia. Open Journal of Psychiatry, 06(01), 8-19. DOI: https://doi.org/10.4236/ojpsych.2016.61002 